\title{
Small-Scale Assays for Studying Dissolution of Pharmaceutical Cocrystals for Oral Administration
}

\author{
Karl J. Box, ${ }^{1}$ John Comer, ${ }^{1}$ Robert Taylor, ${ }^{1}$ Shyam Karki, ${ }^{2}$ Rebeca Ruiz, ${ }^{1}$ Robert Price, ${ }^{3}$ and Nikoletta Fotaki ${ }^{3,4}$
}

Received 15 February 2015; accepted 7 July 2015; published online 25 July 2015

\begin{abstract}
The purpose of this study was to better understand the dissolution properties and precipitation behavior of pharmaceutical cocrystals of poorly soluble drugs for the potential for oral administration based on a small-scale dissolution assay. Carbamazepine and indomethacin cocrystals with saccharin and nicotinamide as coformers were prepared with the sonic slurry method. Dissolution of the poorly soluble drugs indomethacin and carbamazepine and their cocrystals was studied with a small-scale dissolution assay installed on a SiriusT3 instrument. Two methodologies were used: (i) surface dissolution of pressed tablet $(3 \mathrm{~mm})$ in $20 \mathrm{~mL}$ running for fixed times at four $\mathrm{pH}$ stages $(\mathrm{pH} 1.8, \mathrm{pH} 3.9, \mathrm{pH} 5.4, \mathrm{pH}$ 7.3) and (ii) powder dissolution ( $2.6 \mathrm{mg}$ ) in $2 \mathrm{~mL}$ at a constant $\mathrm{pH}$ ( $\mathrm{pH} 2)$. Improved dissolution and useful insights into precipitation kinetics of poorly soluble compounds from the cocrystal form can be revealed by the smallscale dissolution assay. A clear difference in dissolution/precipitation behaviour can be observed based on the characteristics of the coformer used.
\end{abstract}

KEY WORDS: carbamazepine; cocrystal; indomethacin; precipitation; small-scale dissolution.

\section{INTRODUCTION}

Poor solubility is a major issue for the development of new compounds as it can impact on the bioavailability. Several strategies have been developed in order to improve solubility, and the cocrystal strategy is one of them $(1,2)$. Cocrystals are crystalline materials comprising of at least two different components, but the exact definition has created a lot of discussion in the literature related mainly to the properties of these components (3-6). According to the FDA, cocrystals are defined as 'solids that are crystalline materials composed of two or more molecules in the same crystal lattice' (7). Various approaches have been described in the literature for obtaining cocrystals, such as solution evaporation, mechanical grinding, melt extrusion, slurry and melt crystallization $(5,8,9)$.

The differences in molecular arrangements and solid-state thermodynamics can lead to significant changes in physicochemical and pharmacokinetic (PK) properties (10). Cocrystals can significantly increase the bioavailability of poorly soluble compounds based on limited animal bioavailability studies (11-14), but it should be noted that up to now, there are no human bioavailability studies available to validate the cocrystal effect on human pharmacokinetics. Some general conclusions

\footnotetext{
${ }^{1}$ Sirius Analytical Ltd., Forest Row, East Sussex, UK.

${ }^{2}$ Prosonix, Oxford, UK.

${ }^{3}$ Department of Pharmacy and Pharmacology, University of Bath, Claverton Down, Bath, BA2 7AY, UK.

${ }^{4}$ To whom correspondence should be addressed. (e-mail: n.fotaki@bath.ac.uk)
}

concerning cocrystal effects on pharmacokinetics can be revealed by an analysis performed by Shan et al. (10) based on animal data from 64 cocrystals involving 21 APIs, with $80 \%$ of the studied APIs from BCS class II (10). Qualitative analysis between PK and solubility data of cocrystals led to a relatively strong positive correlation between AUC and solubility and to a strong negative correlation between solubility and Tmax for highly permeable APIs. Interestingly, cocrystallization might not only impact drug absorption but also change other aspects of drug pharmacokinetics such as changes of drug distribution, metabolism and excretion especially when a biologically active coformer is used (10).

The physical and chemical properties of cocrystals have been extensively investigated (4). The selection of the coformer is a key issue, and prediction of the crystal structure based solely on the molecular structure of a compound remains a challenge (10). Depending on the choice of coformer, the API solubility enhancement from the cocrystal may vary considerably, from less than 1 to values in excess of 100 -fold (2).

Dissolution testing can play an important role in several areas of drug development as a quality control tool and as an in vitro surrogate for in vivo performance. Most of the published dissolution studies with cocrystals have been reviewed by Thakuria et al. 2013 (5). These are mainly studies of intrinsic dissolution rates measured in simple buffers or in biorelevant media and estimated on the basis of their individual molar extinction coefficients in the respective medium, with the use of simple set ups or compendial apparatus (i.e. USP Apparatus 2) (15-18).

Experimental dissolution data for cocrystals would represent many complex processes occurring simultaneously, such as 
the change of the solid form and of the surface area of the particles as cocrystals undergo solution-mediated phase transformation $(8,19)$. The relationship between the transformation rate and the dissolution rate is critical (15). The increase of the solubility of an API as a result of cocrystal formation often leads to transformation back into the pure API. In the case where the solubility of the cocrystal is higher than the solubility of the API, and the coformer and the API dissociate completely in solution, dissolution will lead to a supersaturated solution with the likelihood of API precipitation (6).

An appropriately designed dissolution experiment would provide useful information relevant to the transformation of cocrystals and the absorption of the API. The importance of experimental set up and type of coformer for the enhanced dissolution properties of cocrystals was demonstrated for carbamazepine cocrystals (9). The use of an open system (flowthrough cell apparatus) and media with a physiologically relevant amount of surfactant provided a discriminatory dissolution method for the cocrystals, driven by the characteristics of the coformer used. Additionally, there has been a trend towards using novel low volume dissolution assays that are API sparing and can help with early development stage decisions for candidate progression. The European Union funded OrBiTo (Oral Biopharmaceutics Tools) project highlights such an initiative and brings together academia and industry in an attempt to develop new in vivo predictive dissolution methodologies (20).

In this paper, we describe small-scale tablet and powder dissolution assays that can be used to assess cocrystal behaviour. As well as using only small quantities of material, a feature of these experiments is the capability to directly control and change $\mathrm{pH}$ in situ which reveals interesting features with respect to dissolution and re-precipitation of the parent drug.

Indomethacin and carbamazepine were selected as the model compounds. They are classified as BCS Class II compounds with low aqueous solubility. Saccharin (SAC; sulphonic acid derivative $\mathrm{pKa}=1.2$ ) and nicotinamide (NIC; pKa 3.3) were the coformers selected for this study. Cocrystals were prepared using the sonic slurry method $(9,21)$.

\section{MATERIALS AND METHODS}

\section{Materials}

Sodium dihydrogen phosphate and hydrochloric acid were purchased from Sigma-Aldrich, UK; sodium acetate was purchased from Fisher Scientific, UK; and potassium chloride was obtained from SureChem Ltd., UK. These reagents were used to prepare the dissolution medium. Potassium hydroxide (Fisher Scientific) was used to adjust $\mathrm{pH}$ in the tablet dissolution assays.

Carbamazepine (99\%) and saccharin (>98\%) were purchased from Acros Organics, and indomethacin and nicotinamide were purchased from Sigma-Aldrich. Indomethacin and carbamazepine cocrystals with saccharin and nicotinamide as coformers on a 1:1 molar ratio were prepared at Prosonix using the sonic slurry method whereby both API and coformer were introduced into an antisolvent and ultrasound applied. In summary, the API and the coformer were transferred to $400 \mathrm{~mL}$ ethyl acetate contained in a jacketed vessel with a side port for an ultrasound probe. The reaction temperature was maintained at $\sim 15^{\circ} \mathrm{C}$, and an ultrasound power of $30 \mathrm{~W}$ was applied. The slurry was stirred at a stirring rate of approximately $60 \mathrm{rpm}$ and the resulting slurry was filtered. The resulting solid was dried under vacuum at $35^{\circ} \mathrm{C}$ overnight. The acoustic cavitation induces nucleation and crystallization leading to the formation of well-defined cocrystals as physically characterized by scanning electron microscopy, differential scanning calorimetry, X-ray powder diffraction and particle size analysis $(9,22,23)$.

\section{METHODS}

\section{In Vitro Dissolution Testing}

Dissolution of indomethacin and carbamazepine and the two cocrystals was studied at $25^{\circ} \mathrm{C}$ with a small-scale dissolution assay installed on a SiriusT3 instrument (Sirius Analytical Instruments, East Sussex, UK) (24) (Table I). The SiriusT3 is an automatic titration system incorporating in situ UV spectroscopy, which is specifically designed for the measurement of various physiochemical properties, including $\mathrm{pKa}, \log \mathrm{P}$ and solubility, as well as dissolution.

The dissolution medium was prepared as $10 \mathrm{mM}$ phosphate and $10 \mathrm{mM}$ acetate pre-adjusted to a starting $\mathrm{pH}$ of 1.8 or $\mathrm{pH} 2$ (using $\mathrm{HCl}$ ) and in a background of $0.15 \mathrm{M} \mathrm{KCl}$. Potassium hydroxide was used to raise $\mathrm{pH}$ in the tablet dissolution assays as described below.

Dissolution samples were used either directly as $\sim 2.5 \mathrm{mg}$ powders or were prepared as tablets with a diameter of $3 \mathrm{~mm}$, requiring approximate sample weights of 5-10 $\mathrm{mg}$. This was carried out by using a modified Specac tablet press (Specac Ltd, Orpington, UK) incorporating a load cell for consistent pressure readings. The press is used with a set of tablet dies (3 mm diameter) to press powder of pure drug or cocrystal directly into a tablet. Tablets were prepared using an $80-\mathrm{kg}$ load force applied for a period of 2 min until the pressure readings remained constant, i.e. pressure readings reduce under initial compaction and so the force is increased again to maintain the $80-\mathrm{kg}$ load. All tablets were then visually examined to ensure that their surfaces were smooth and free of visible defects and the tablets were placed in tablet holders and held in situ by an O-ring seal, so that only one side of the tablet is exposed to the dissolution medium.

The powder dissolution experiments consisted of $2 \mathrm{~mL}$ of the phosphate-acetate buffer medium adjusted to $\mathrm{pH} \mathrm{2,} \mathrm{to}$ represent behaviour at a gastric $\mathrm{pH}$ value, and added at the start of the dissolution experiment. For the tablets, $20 \mathrm{~mL}$ of the phosphate-acetate dissolution medium was adjusted to $\mathrm{pH}$ 1.8 and added at the start of the dissolution experiment. The dissolution of the powders or tablets was directly monitored by multi-wavelength UV absorption spectroscopy using an in situ fibre-optic UV probe (Fig. 1). Dissolution data (UV spectra) were recorded for $240 \mathrm{~min}$ at $\mathrm{pH} 2$, for the powders. For the tablets, dissolution data were recorded for $60 \mathrm{~min}$ at gastric $\mathrm{pH} 1.8$, after which the $\mathrm{pH}$ was increased by dispensing $\mathrm{KOH}$ via a capillary, to simulate the $\mathrm{pH}$ transition occurring in the gastrointestinal tract. In the intestinal $\mathrm{pH}$ phase, $\mathrm{KOH}$ solution was added to raise the $\mathrm{pH}$ to 3.9 and UV spectra were collected for a further $30 \mathrm{~min}$. This process was continued stepwise by increasing the $\mathrm{pH}$ to 5.4 and 7.3 and collecting UV spectra for an additional $30 \mathrm{~min}$ at each $\mathrm{pH}$. Stirring of the solution was continuous and at a constant rate. After the 
Table I. Conditions of Dissolution Experiments

\begin{tabular}{|c|c|c|c|c|c|}
\hline Experiment & Dissolution medium & Sector 1 & Sector 2 & Sector 3 & Sector 4 \\
\hline Powder dissolution & $\begin{array}{l}10 \mathrm{mM} \text { phosphate } \\
\text { buffer-10 mM } \\
\text { acetate buffer } \\
\text { adjusted to } \mathrm{pH} 2\end{array}$ & $\begin{array}{l}\text { UV spectra recorded } \\
\text { for } 240 \text { min at } \mathrm{pH} 2\end{array}$ & $\mathrm{n} / \mathrm{a}$ & $\mathrm{n} / \mathrm{a}$ & $\mathrm{n} / \mathrm{a}$ \\
\hline $\begin{array}{l}\text { Pressed tablet } \\
\text { dissolution }\end{array}$ & $\begin{array}{l}10 \mathrm{mM} \text { phosphate } \\
\text { buffer-10 } \mathrm{mM} \\
\text { acetate buffer } \\
\text { adjusted to } \mathrm{pH} 1.8\end{array}$ & $\begin{array}{l}\text { UV spectra recorded } \\
\text { for } 60 \text { min at } \mathrm{pH} 1.8\end{array}$ & $\begin{array}{l}\text { UV spectra recorded } \\
\text { for } 30 \text { min at } \mathrm{pH} 3.9^{a}\end{array}$ & $\begin{array}{l}\text { UV spectra recorded } \\
\text { for } 30 \mathrm{~min} \text { at } \mathrm{pH} 5.4^{a}\end{array}$ & $\begin{array}{l}\text { UV spectra } \\
\text { recorded } \\
\text { for } 30 \mathrm{~min} \\
\text { at } \mathrm{pH} 7.4^{a}\end{array}$ \\
\hline
\end{tabular}

${ }^{a}$ Sector $\mathrm{pH}$ reached by in situ addition of $\mathrm{KOH}$

experiment, the UV absorption data were converted to an absolute sample weight using previously determined, $\mathrm{pH}$-dependent, molar extinction coefficients.

Molar extinction coefficients and pKas of the compounds were determined by UV-metric titration using the SiriusT3. The UV-metric method allowed the determination of molar extinction coefficients for neutral and ionized forms of a sample from a single experiment. Samples were typically prepared as 5-mM stock solutions in DMSO and titrated between $\mathrm{pH} 2$ and $\mathrm{pH} 12$ in $1.5 \mathrm{~mL}$ of $0.15 \mathrm{M}$ aqueous $\mathrm{KCl}$. Sample concentrations were optimized in order to obtain a peak UV absorbance of approximately 1 absorbance unit.

\section{Dissolution Profile Comparisons}

The difference between the mean dissolution data sets was assessed with the difference factor, $f_{1}$, as described by Moore and Flanner (25). The difference factor was evaluated for the whole duration of the experiment

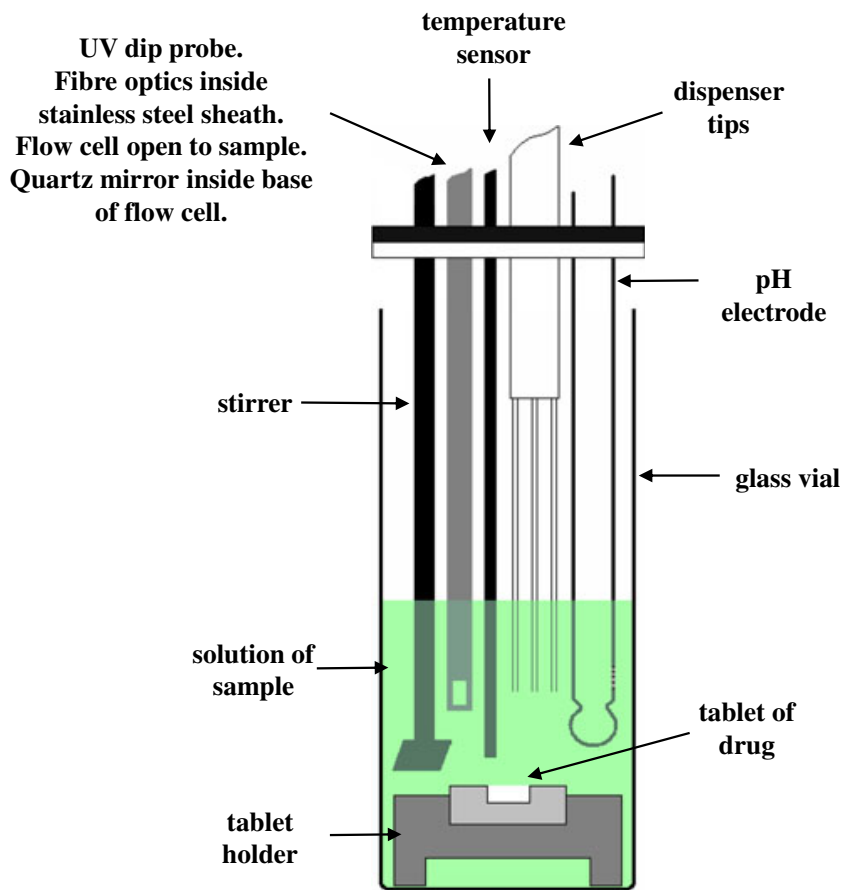

Fig. 1. Small-scale dissolution assay (Sirius system) (up to $4 \mathrm{~h}$ ). The dissolution data of the pure API were used as the reference data set when comparisons between the API and the cocrystal dissolution data set were performed, whereas the dissolution data of the saccharin cocrystal were used as the reference data set when comparisons between the dissolution performance of the two cocrystals were made. In the present study, a value of $f_{1}$ higher than 15 was set as the limit for identifying differences between the samples.

\section{RESULTS}

\section{Indomethacin (IND) and Its Cocrystals (IND-SAC, IND-NIC)}

Surface Dissolution of Pressed Tablet. The dissolution profile of the tablet of indomethacin shows that $4.0 \pm 0.3 \mu \mathrm{g}$ of API was released by the end of the first sector at $\mathrm{pH}$ 1.8. By comparison, $19 \pm 3 \mu \mathrm{g}$ of indomethacin was released from the indomethacin-saccharin cocrystal and $31 \pm 7 \mu \mathrm{g}$ from the indomethacin-nicotinamide cocrystal (Fig. 2 and Table II). By the end of the second sector, at $\mathrm{pH} 3.9$, the amounts of dissolved indomethacin increased to $5.1 \pm 0.9,25$ \pm 2 and $33 \pm 6 \mu \mathrm{g}$ for the IND, IND-SAC and IND-NIC, respectively. When the $\mathrm{pH}$ of the dissolution medium rises above the pKa value (4.13) of indomethacin, there was a significant increase in the amount of indomethacin released

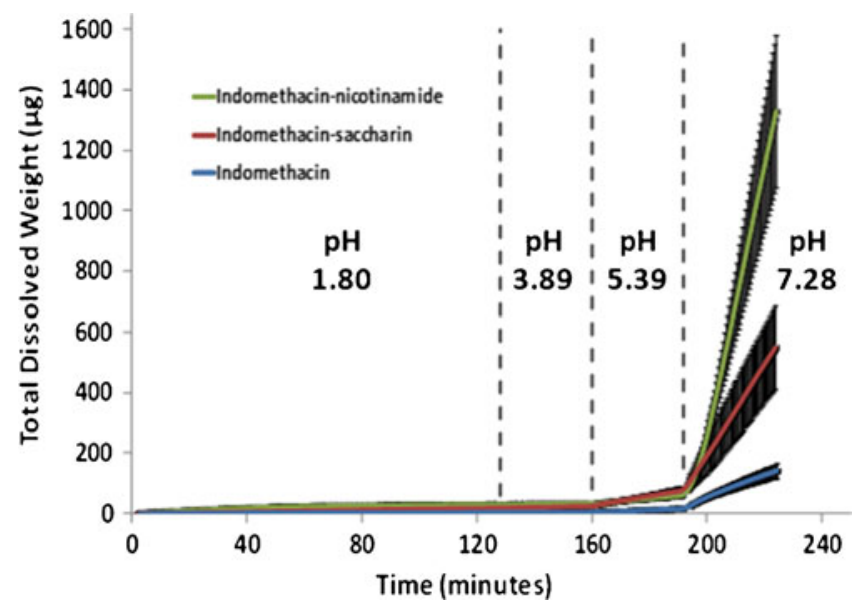

Fig. 2. Dissolution of indomethacin and cocrystal pressed tablets $(n=3)$ over four $\mathrm{pH}$ sectors 
Table II. Summary of Tablet and Powder Dissolution Results for Indomethacin and Its Cocrystals $(n=3 ; \pm$ SD)

\begin{tabular}{|c|c|c|c|}
\hline Amount dissolved indomethacin & IND tablet $^{a}(\mu \mathrm{g})$ & IND-SAC tablet $^{a}(\mu \mathrm{g})$ & IND-NIC tablet $^{a}(\mu \mathrm{g})$ \\
\hline End of sector $1(\mathrm{pH} 1.8)$ & $4.0 \pm 0.3$ & $19 \pm 3$ & $31 \pm 7$ \\
\hline End of sector 2 (pH 3.9) & $5.1 \pm 0.9$ & $25 \pm 2$ & $33 \pm 6$ \\
\hline End of sector 3 ( $\mathrm{pH} 5.4)$ & $17 \pm 3$ & $76 \pm 14$ & $61 \pm 9$ \\
\hline \multirow[t]{2}{*}{ End of sector $4(\mathrm{pH} 7.3)$} & $141 \pm 24$ & $549 \pm 137$ & $1327 \pm 252$ \\
\hline & IND powder ${ }^{b}(\mu \mathrm{g})$ & IND-SAC powder $^{b}(\mu \mathrm{g})$ & IND-NIC powder $^{b}(\mu \mathrm{g})$ \\
\hline After $3 \mathrm{~min}$ & $0.3 \pm 0.1$ & $26 \pm 3$ & $24 \pm 1$ \\
\hline Peak concentration (time) & $4.1 \pm 0.3(4 \mathrm{~h})$ & $34 \pm 2(7 \mathrm{~min})$ & $45 \pm 3(13 \mathrm{~min})$ \\
\hline Final amount & $4.1 \pm 0.3$ & $19 \pm 2$ & $14 \pm 1$ \\
\hline
\end{tabular}

${ }^{a}$ Experiments performed in $20 \mathrm{~mL}$ volume

${ }^{b}$ Experiments performed in $2 \mathrm{~mL}$ volume at $\mathrm{pH} 2$

from both the tablets of the drug and of the cocrystals (21). The respective amounts dissolved at the end of the third sector ( $\mathrm{pH} 5.4$ ) were $17 \pm 3,76 \pm 14$ and $61 \pm 9 \mu \mathrm{g}$ for the IND, IND-SAC and IND-NIC with the IND-SAC showing the greatest amount released. At the end of the final $\mathrm{pH}$ sector ( $\mathrm{pH} 7.4)$, the indomethacin-nicotinamide once again showed the greatest release with dissolved amounts of indomethacin at $141 \pm 24,549 \pm 137$ and $1327 \pm 252 \mu \mathrm{g}$ for the IND, IND-SAC and IND-NIC.

Powder Dissolution. The powder dissolution of all samples under constant $\mathrm{pH}$ (Fig. 3 and Table II) revealed the solubilization enhancement of the drug from the cocrystal samples and also provided information regarding the precipitation and kinetic solubility of the samples. Dissolution of indomethacin from the indomethacin-saccharin cocrystal was similar to the indomethacin-nicotinamide cocrystal reaching $26 \pm 3 \mu \mathrm{g}$ for IND-SAC versus $24 \pm 1 \mu \mathrm{g}$ for INDNIC in the first $3 \mathrm{~min}$. The onset of precipitation of the free indomethacin that was released at $\mathrm{pH} 2$ occurred sooner for the IND-SAC cocrystal compared to the IND-NIC cocrystal. The amount of dissolved indomethacin released from the IND-SAC cocrystal peaked at $34 \pm 2 \mu \mathrm{g}$ after 7 min whilst it peaked at $45 \pm 3 \mu \mathrm{g}$ after $13 \mathrm{~min}$ from the IND-NIC cocrystal. The final concentrations of dissolved indomethacin at the end of the experiments were $19 \pm 2 \mu \mathrm{g}$ for IND-SAC and 14 $\pm 1 \mu \mathrm{g}$ for IND-NIC suggesting that equilibrium solubility had been achieved for the precipitating form. By comparison, the amount of dissolved indomethacin from the pure API reached

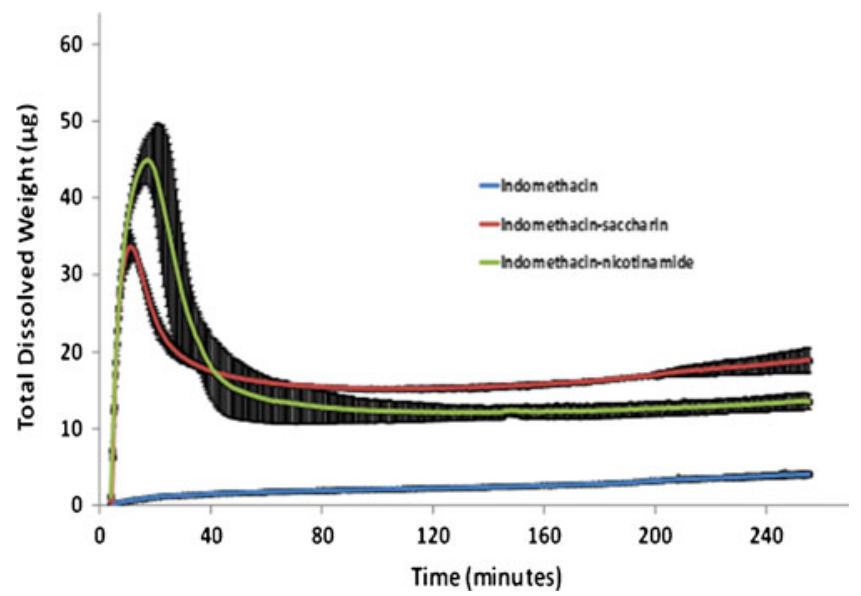

Fig. 3. Dissolution of indomethacin and cocrystal powders $(n=3)$ at $\mathrm{pH} 2$ only $0.3 \pm 0.1 \mu \mathrm{g}$ after $3 \mathrm{~min}$ and it was still dissolving by the end of the experiment where it had reached a level of $4.1 \pm 0.3 \mu \mathrm{g}$ after $4 \mathrm{~h}$.

\section{Carbamazepine (CBZ) and Its Cocrystals (CBZ-SAC, CBZ-NIC)}

Surface Dissolution of Pressed Tablet. Dissolution profiles from the tablets of the drug and of the cocrystals (Fig. 4 and Table III) revealed some interesting behaviour. The saccharin cocrystal had the highest solubilization followed by carbamazepine API, and then the nicotinamide cocrystal was the lowest. Also, there was little dependence on $\mathrm{pH}$ and the dissolution profiles showed a continual release, as one process, over all of the $\mathrm{pH}$ sectors. The amount of carbamazepine released from the pure drug was $368 \pm 26 \mu \mathrm{g}$ at the end of the first sector ( $\mathrm{pH} 1.8$ ), $429 \pm 42 \mu \mathrm{g}$ at the end of the second sector $(\mathrm{pH} 3.9)$ and 480 $\pm 61 \mu \mathrm{g}$ and $519 \pm 87 \mu \mathrm{g}$ at the end of the third (pH 5.4) and fourth ( $\mathrm{pH} 7.3$ ) sectors. The corresponding amounts of released carbamazepine from the CBZ-NIC cocrystal were $215 \pm 19 \mu \mathrm{g}(\mathrm{pH}$ 1.8), 261 $\pm 21 \mu \mathrm{g}(\mathrm{pH} 3.9), 301 \pm 26 \mu \mathrm{g}(\mathrm{pH} 5.4)$ and $340 \pm 29 \mu \mathrm{g}$ (pH 7.3) and from the CBZ-SAC cocrystal were $469 \pm 28 \mu \mathrm{g}(\mathrm{pH}$ 1.8), $541 \pm 26 \mu \mathrm{g}(\mathrm{pH} 3.9), 596 \pm 26 \mu \mathrm{g}(\mathrm{pH} 5.4)$ and $642 \pm 23 \mu \mathrm{g}(\mathrm{pH}$ 7.3). Whilst carbamazepine itself is a non-ionisable compound, both the coformers, nicotinamide and saccharin, are ionisable with pKa values, measured in this work, of 3.3 (basic) and 1.2 (acidic), respectively.

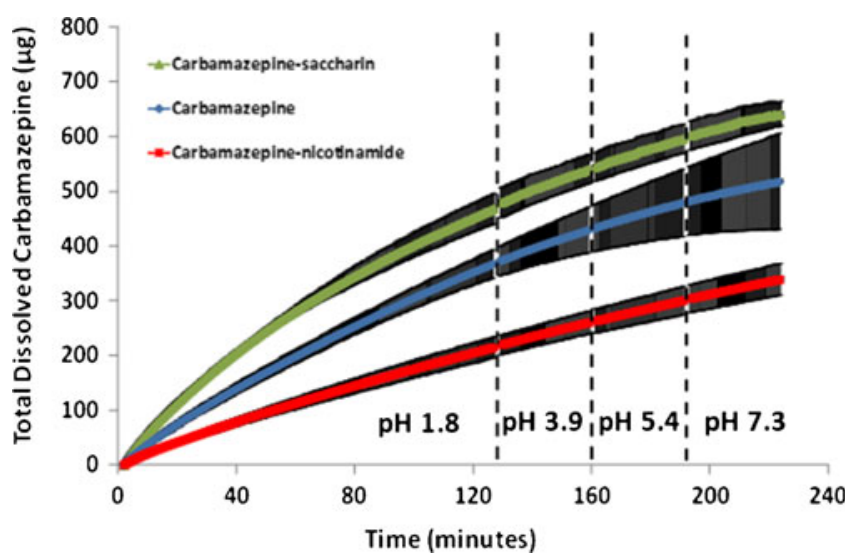

Fig. 4. Dissolution of carbamazepine and cocrystal pressed tablets $(n=3)$ over four $\mathrm{pH}$ sectors 
Table III. Summary of Tablet and Powder Dissolution Results for Carbamazepine and Its Cocrystals $(n=3 ; \pm$ SD)

\begin{tabular}{|c|c|c|c|}
\hline Amount dissolved carbamazepine & CBZ tablet ${ }^{a}(\mu \mathrm{g})$ & CBZ-SAC tablet $^{a}(\mu \mathrm{g})$ & CBZ-NIC tablet $^{a}(\mu \mathrm{g})$ \\
\hline End of sector $1(\mathrm{pH} 1.8)$ & $368 \pm 26$ & $469 \pm 28$ & $215 \pm 19$ \\
\hline End of sector 2 (pH 3.9) & $429 \pm 42$ & $541 \pm 26$ & $261 \pm 21$ \\
\hline End of sector 3 (pH 5.4) & $480 \pm 61$ & $596 \pm 26$ & $301 \pm 26$ \\
\hline \multirow[t]{2}{*}{ End of sector $4(\mathrm{pH} 7.3)$} & $519 \pm 87$ & $642 \pm 23$ & $340 \pm 29$ \\
\hline & CBZ powder ${ }^{b}(\mu \mathrm{g})$ & CBZ-SAC powder ${ }^{b}(\mu \mathrm{g})$ & CBZ-NIC powder ${ }^{b}(\mu \mathrm{g})$ \\
\hline After $90 \mathrm{~s}$ & $27 \pm 4$ & $114 \pm 2$ & $152 \pm 9$ \\
\hline Peak concentration (time) & $370 \pm 5(77 \mathrm{~min})$ & $371 \pm 24(11 \mathrm{~min})$ & $197 \pm 47(2 \mathrm{~min})$ \\
\hline Final amount & $285 \pm 7$ & $277 \pm 10$ & $70 \pm 27$ \\
\hline
\end{tabular}

${ }^{a}$ Experiments performed in $20 \mathrm{~mL}$ volume

${ }^{b}$ Experiments performed in $2 \mathrm{~mL}$ volume at $\mathrm{pH} 2$

Powder Dissolution. The powder dissolution of all samples under constant $\mathrm{pH} 2$ revealed that carbamazepine dissolved much more slowly from the carbamazepine sample than from the cocrystal samples and also provided information regarding the precipitation and kinetic solubility of the samples (Fig. 5 and Table III). The amount of dissolved carbamazepine reached 152 $\pm 9 \mu \mathrm{g}$ from the CBZ-NIC cocrystal and $114 \pm 2 \mu \mathrm{g}$ from the CBZSAC in the first $90 \mathrm{~s}$ whilst CBZ reached only $27 \pm 4 \mu \mathrm{g}$ in the same time. The samples continued to dissolve reaching peak concentrations of $197 \pm 47 \mu \mathrm{g}$ for CBZ-NIC after $2 \mathrm{~min}, 371 \pm 24 \mu \mathrm{g}$ for CBZ-SAC after $11 \mathrm{~min}$ and $370 \pm 5 \mu \mathrm{g}$ after $77 \mathrm{~min}$ for pure CBZ. The drop in concentration observed following dissolution of the pure CBZ is probably due to the formation of the less soluble carbamazepine dihydrate form (26). The concentration decreased to $285 \pm 7 \mu \mathrm{g}$ of dissolved carbamazepine by the end of the 4-h experiment. Precipitation of carbamazepine from the CBZ-SAC cocrystal occurred at a much earlier time, and the final dissolved concentration reached a similar level at $277 \pm 10 \mu \mathrm{g}$ after $4 \mathrm{~h}$. Dissolution of carbamazepine from the CBZ-NIC cocrystal was faster than from the CBZ-SAC cocrystal and produced a heavily turbid solution as the carbamazepine precipitated from solution after $2 \mathrm{~min}$. The final amount of dissolved carbamazepine from the CBZ-NIC experiments was $70 \pm 27 \mu \mathrm{g}$ after $130 \mathrm{~min}$.

\section{DISCUSSION}

Small-scale dissolution assays (24) can be used to illustrate the different behaviour of the cocrystals (i) with respect

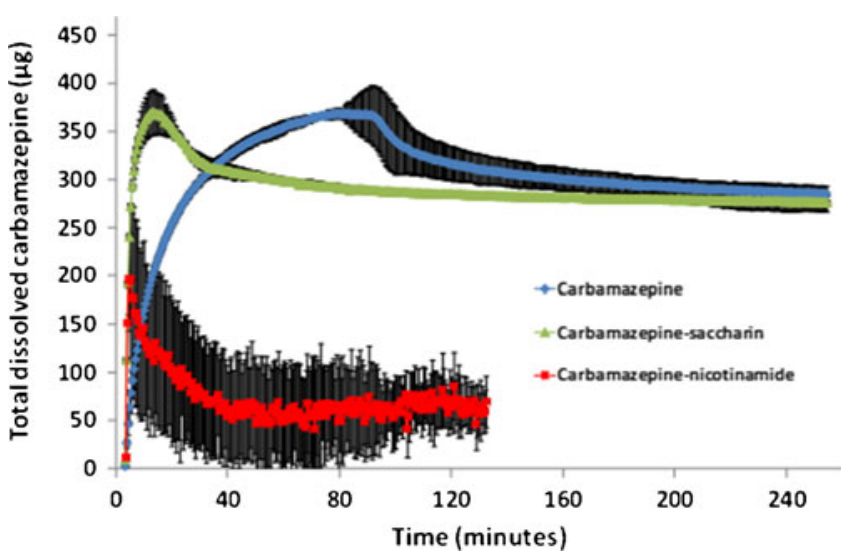

Fig. 5. Dissolution of carbamazepine and cocrystal powders $(n=3)$ at $\mathrm{pH} 2$ to pressed tablet dissolution as a function of $\mathrm{pH}$ and (ii) solubilization capacity and precipitation behaviour of powder samples at $\mathrm{pH} 2$.

For the dissolution of tablets, cocrystals with indomethacin dissolved faster than pure indomethacin, and the greatest solubilization occurred, in all cases, above the pKa value (4.13) of indomethacin when it becomes negatively charged (Fig. 2 and Table II). A comparison of the tablet dissolution profiles provided $f_{1}$ values of 283 and 618 for the IND-SAC tablet and the IND-NIC tablet, respectively, when compared to the IND tablet. The dissolution profile of the IND-NIC tablet was substantially different than the dissolution profile of the IND-SAC tablet $\left(f_{1}=90\right)$. The tablets were prepared using an $80-\mathrm{kg}$ load force applied for a period of 2 min until the pressure readings remained constant, and all tablets were visually examined to ensure their surfaces were smooth and free of visible defects. It was therefore thought unlikely that the compaction force would have a strong influence on the differences observed between the dissolution profiles, as was demonstrated in a recent publication on tablet dissolution of indomethacin crystalline forms (27).

Powder dissolution of pure indomethacin at $\mathrm{pH} 2$ was very low for the duration of the assay reaching only $4 \mu \mathrm{g}$ in the $2 \mathrm{~mL}$ volume and showing the poor solubility of the free form of the API. The powders of the cocrystals had improved dissolution performance, but precipitation could not be prevented as the solubility limit of indomethacin was soon exceeded as it was released from the cocrystal (Fig. 3 and Table II). Maximum solubilization from the IND-SAC cocrystal was $17 \mu \mathrm{g} / \mathrm{mL}$ and from the IND-NIC cocrystal $23 \mu \mathrm{g} / \mathrm{mL}$. After precipitation, both cocrystals reached a similar concentration of $7 \mu \mathrm{g} / \mathrm{mL}$ for INDNIC and $8 \mu \mathrm{g} / \mathrm{mL}$ for IND-SAC after $\sim 90 \mathrm{~min}$ but this was still much higher than the solubility of the crystalline form of indomethacin $(2 \mu \mathrm{g} / \mathrm{mL})$. A comparison of the powder dissolution profiles provided $f_{1}$ values of 627 and 554 for the IND-SAC powder sample and the IND-NIC powder sample, respectively, when compared to the IND powder sample. The dissolution profile of the IND-NIC powder sample was different than the dissolution profile of the IND-SAC powder sample $\left(f_{1}=25\right)$.

Tablet dissolution of carbamazepine and its cocrystals showed similarly shaped release profiles for the amount of carbamazepine entering the solution (Fig. 4 and Table III). However, only the CBZ-SAC cocrystal provided enhanced solubilization of carbamazepine whereas the CBZ-NIC cocrystal showed much less carbamazepine going into solution and a slower dissolution rate, when compared to the pure carbamazepine. A comparison of the tablet dissolution profiles provided $f_{1}$ values of 30 and 40 for the CBZ-SAC tablet 
and the CBZ-NIC tablet, respectively, when compared to the CBZ tablet. The dissolution profile of the CBZ-NIC tablet was significantly different than the dissolution profile of the CBZ-SAC tablet $\left(f_{1}=54\right)$. In this case also, as for the indomethacin and the indomethacin cocrystal tablets, carbamazepine tablets and carbamazepine cocrystal tablets were prepared using an $80-\mathrm{kg}$ load force applied for a period of 2 min until the pressure readings remained constant and all tablets were visually examined to ensure their surfaces were smooth and free of visible defects. It was also thought unlikely that the compaction force would have a strong influence on comparison of the release profiles. Thus, the substantial difference between the amounts dissolved from the cocrystals tablets and the API tablets at various time intervals (as indicated by the $f_{1}$ values) can be attributed to the differences in the physicochemical properties of the samples tested.

Powder dissolution of carbamazepine at $\mathrm{pH} 2$ reached $185 \mu \mathrm{g} /$ $\mathrm{mL}$ before precipitating after $77 \mathrm{~min}$. The precipitation event probably represents transformation to the less soluble dihydrate form (26). The powder of the CBZ-SAC cocrystal had a faster initial dissolution rate than the $\mathrm{CBZ}$ powder although the peak concentration was the same $(186 \mu \mathrm{g} / \mathrm{mL})$ and precipitation was observed at a much earlier time point $(11 \mathrm{~min})$. The final concentrations after $4 \mathrm{~h}$ dissolution from the carbamazepine powder sample and the CBZ-SAC cocrystal powder sample were also similar at 143 and $139 \mu \mathrm{g} / \mathrm{mL}$ (Fig. 5 and Table III). The initial dissolution of the CBZ-NIC cocrystal powder was rapid $(76 \mu \mathrm{g} / \mathrm{mL}$ in the first $90 \mathrm{~s}$ ), but precipitation occurred very quickly after $2 \mathrm{~min}$ and the peak concentration only reached $99 \mu \mathrm{g} / \mathrm{mL}$. Following precipitation, the final concentration obtained was much lower at $35 \mu \mathrm{g} / \mathrm{mL}$. A comparison of the powder dissolution profiles provided $f_{1}$ values of 20 and 78 for the CBZ-SAC powder sample and the CBZ-NIC powder sample, respectively, when compared to the CBZ powder sample. The dissolution profile of the CBZ-NIC powder sample was significantly different than the dissolution profile of the CBZ-SAC powder sample $\left(f_{1}=76\right)$.

The powder results and tablet results for carbamazepine, on first appearances, seem to be showing different behaviour to each other. The CBZ-NIC cocrystal dissolved so rapidly as a powder that it released free carbamazepine that precipitated almost immediately resulting in very poor solubility. The CBZNIC tablet dissolved slower by comparison, but similarly, it also ended up with the lowest amount of total dissolved carbamazepine. We hypothesize that as nicotinamide is released from the surface, insoluble carbamazepine is left behind and coats the surface of the tablet thus retarding further dissolution. Hence, for both the tablet and powder assays, we ended up with the least amount of carbamazepine in solution from the CBZ-NIC cocrystal. In future studies, confirmation of form changes by analysis of the solid form remaining at the end of the experiment could provide a clear description of the product remaining after the dissolution. Additionally, the use of in situ Raman technology, which is increasingly being used in tandem with small-scale dissolution methodologies, would directly reveal the nature of such form changes as the experiment progresses (28).

\section{CONCLUSIONS}

Improved dissolution and useful insights into precipitation kinetics of poorly soluble compounds from the cocrystal form can be revealed by the small-scale dissolution assay. A clear difference in dissolution/precipitation behaviour can be observed based on the characteristics of the coformer used. An increase in dissolution of indomethacin and carbamazepine from cocrystals would lead to an expectation of increased oral absorption of these highly permeable BCS Class II compounds due to increased solubilization. However, improved dissolution kinetics should be tempered against faster drug precipitation kinetics during selection of a coformer and a balance struck to achieve optimum performance.

Small-scale dissolution assays can be easily set up on the SiriusT3 to screen a selection of candidate cocrystals (or salts or polymorphs) during early development under a variety of conditions (powders, compacts, gastric and intestinal $\mathrm{pH}$ ).

Future work should be directed towards understanding the solid-state transformations and precipitation behaviour in more detail and how this may impact on the oral absorption of the drugs. Additionally, understanding the impact of formulation additives such as polymeric precipitation inhibitors (polyvinylpyrrolidones or celluloses) would be valuable.

\section{ACKNOWLEDGMENTS}

Part of this work has been previously included in a poster at the AAPS annual meetings in Chicago and San Antonio, October 2012, 2013.

\section{REFERENCES}

1. Miroshnyk I, Mirza S, Sandlert N. Pharmaceutical co-crystals-an opportunity for drug product enhancement. Expert Opin Drug Deliv. 2009;6(4):333-41.

2. Williams HD, Trevaskis NL, Charman SA, Shanker RM, Charman WN, Pouton CW, et al. Strategies to address low drug solubility in discovery and development. Pharmacol Rev. 2013;65(1):315-499.

3. Blagden N, de Matas M, Gavan PT, York P. Crystal engineering of active pharmaceutical ingredients to improve solubility and dissolution rates. Adv Drug Deliv Rev. 2007;59(7):617-30.

4. Schultheiss N, Newman A. Pharmaceutical cocrystals and their physicochemical properties. Cryst Growth Des. 2009;9(6):2950-67.

5. Thakuria R, Delori A, Jones W, Lipert MP, Roy L, RodríguezHornedo N. Pharmaceutical cocrystals and poorly soluble drugs. Int J Pharm. 2013;453(1):101-25.

6. Elder DP, Holm R, Diego HL. Use of pharmaceutical salts and cocrystals to address the issue of poor solubility. Int J Pharm. 2013;453(1):88-100.

7. FDA. US Department of Health and Human Services, Food and Drug Administration, Center for Drug Evaluation and Research (CDER). Guidance for Industry: Regulatory Classification of Pharmaceutical Cocrystals. 2011.

8. Qiao N, Li M, Schlindwein W, Malek N, Davies A, Trappitt G. Pharmaceutical cocrystals: an overview. Int J Pharm. 2011;419(12):1-11.

9. Tomaszewska I, Karki S, Shur J, Price R, Fotaki N. Pharmaceutical characterisation and evaluation of cocrystals: importance of in vitro dissolution conditions and type of coformer. Int J Pharm. 2013;453(2):380-8.

10. Shan N, Perry ML, Weyna DR, Zaworotko MJ. Impact of pharmaceutical cocrystals: the effects on drug pharmacokinetics. Expert Opin Drug Metab Toxicol. 2014;10(9):1255-71.

11. Bak A, Gore A, Yanez E, Stanton M, Tufekcic S, Syed R, et al. The co-crystal approach to improve the exposure of a waterinsoluble compound: AMG 517 sorbic acid co-crystal characterization and pharmacokinetics. J Pharm Sci. 2008;97(9):3942-56.

12. McNamara DP, Childs SL, Giordano J, Iarriccio A, Cassidy J, Shet MS, et al. Use of a glutaric acid cocrystal to improve oral 
bioavailability of a low solubility API. Pharmaceut Res. 2006;23(8):1888-97.

13. Hickey MB, Peterson ML, Scoppettuolo LA, Morrisette SL, Vetter A, Guzman $\mathrm{H}$, et al. Performance comparison of a cocrystal of carbamazepine with marketed product. Eur J Pharm Biopharm. 2007;67(1):112-9.

14. Variankaval N, Wenslow R, Murry J, Hartman R, Helmy R, Kwong E, et al. Preparation and solid-state characterization of nonstoichiometric cocrystals of a phosphodiesterase-IV inhibitor annul L-tartaric acid. Cryst Growth Des. 2006;6(3):690-700.

15. Shiraki K, Takata N, Takano R, Hayashi Y, Terada K. Dissolution improvement and the mechanism of the improvement from cocrystallization of poorly water-soluble compounds. Pharmaceut Res. 2008;25(11):2581-92.

16. Cherukuvada S, Babu NJ, Nangia A. Nitrofurantoin-paminobenzoic acid cocrystal: hydration stability and dissolution rate studies. J Pharm Sci. 2011;100(8):3233-44.

17. Remenar JF, Morissette SL, Peterson ML, Moulton B, MacPhee JM, Guzman HR, et al. Crystal engineering of novel cocrystals of a triazole drug with 1,4-dicarboxylic acids. J Am Chem Soc. 2003;125(28):8456-7.

18. Childs SL, Chyall LJ, Dunlap JT, Smolenskaya VN, Stahly BC, Stahly GP. Crystal engineering approach to forming cocrystals of amine hydrochlorides with organic acids. Molecular complexes of fluoxetine hydrochloride with benzoic, succinic, and fumaric acids. J Am Chem Soc. 2004;126(41):13335-42.

19. Greco K, Bogner R. Solution-mediated phase transformation: significance during dissolution and implications for bioavailability. J Pharm Sci. 2011 Dec 27.

20. Bergstrom CA, Holm R, Jorgensen SA, Andersson SB, Artursson $\mathrm{P}$, Beato S, et al. Early pharmaceutical profiling to predict oral drug absorption: current status and unmet needs. Eur J Pharm Sci. 2014;57:173-99.

21. Comer J, Judge S, Matthews D, Towes L, Falcone B, Goodman J, et al. The intrinsic aqueous solubility of indomethacin. ADMET \& DMPK. 2014;2(1):18-32.

22. Box K, Comer J, Mole J, Taylor R, Fotaki N. Small scale assays for studying dissolution and precipitation of pharmaceutical cocrystals. AAPS Journal 2012. abstracts Available from http:// www.aapsj.org/AAPS annual meeting, Chicago. 2012.

23. Box K, Comer J, Mole J, Taylor R, Fotaki N. Dissolution and precipitation studies of carbamazepine cocrystals with small scale assays. AAPS Journal. abstracts. Available from http:// www.aapsj.org/AAPS annual meeting, San Antonio. 2013.

24. Gravestock T, Box K, Comer J, Frake E, Judge S, Ruiz R. The "GI dissolution" method: a low volume, in vitro apparatus for assessing the dissolution/precipitation behaviour of an active pharmaceutical ingredient under biorelevant conditions. Anal Methods. 2011;3(3):560-7. doi:10.1039/C0AY00434K.

25. Moore JW, Flanner HH. Mathematical comparison of curves with an emphasis on in vitro dissolution profiles. Pharm Technol. 1996;20(6):64-74.

26. Tian F, Zeitler JA, Strachan CJ, Saville DJ, Gordon KC, Rades T. Characterizing the conversion kinetics of carbamazepine polymorphs to the dihydrate in aqueous suspension using Raman spectroscopy. J Pharm Biomed Anal. 2006;40(2):271-80.

27. Lobmann K, Flouda K, Qiu D, Tsolakou T, Wang W, Rades T. The influence of pressure on the intrinsic dissolution rate of amorphous indomethacin. Pharmaceutics. 2014;6(3):481-93.

28. Østergaard J, Wu JX, Naelapää K, Boetker JP, Jensen H, Rantanen J. Simultaneous UV imaging and Raman spectroscopy for the measurement of solvent-mediated phase transformations during dissolution testing. J Pharm Sci. 2014;103(4):1149-56. 